\title{
Chapter 9 \\ New Food Technologies in Europe, \\ India and China
}

\author{
David Coles, Sachin Chaturvedi, Qiang Li and Miltos Ladikas
}

\subsection{Historical Developments in Food and Agriculture}

The past 20-30 years have seen significant changes in the way in which food security, safety and the food economy have developed. These changes are due inter alia to advances in technology, together with changes in the roles of stakeholders and increasing awareness of ethical considerations that incorporate consumer perceptions, animal welfare and environmental issues, and may vary according to local cultural influences.

\subsection{The European Case}

Over the past three decades, the dominant agri-industrial food production system in Europe has been challenged by a post-productivist model that is popularly perceived as more environment-friendly and grass-roots-initiated. This shift is a consequence

D. Coles $(\varangle) \cdot$ M. Ladikas

Centre for Professional Ethics, School of Health, University of Central Lancashire,

Brook 230, Preston PR1 2HE, UK

e-mail: dcoles1@uclan.ac.uk

M. Ladikas

e-mail: mladikas@uclan.ac.uk

S. Chaturvedi

RIS, Zone IV-B, Fourth Floor, India Habitat Centre, Lodhi Road,

New Delhi 110003, India

e-mail: sachin@ ris.org.in

Q. Li

CASTED, Yu Yuan Tan Nan Lu Rd 8Yu 8, Beijing 100038, China

e-mail: liq@casted.org.cn 
Table 9.1 Food technologies discourse and values: Europe

\begin{tabular}{l|l|l|l}
\hline & Justice and equality & Sustainability & Freedoms and rights \\
\hline Innovation & $\begin{array}{l}\text { Economic develop- } \\
\text { ment; health benefit } \\
\text { effects; unaffordable } \\
\text { products }\end{array}$ & $\begin{array}{l}\text { Disease resistance; } \\
\text { extreme-climate crops; } \\
\text { bioenergy crops }\end{array}$ & $\begin{array}{l}\text { Choice between agri- } \\
\text { industrial and post- } \\
\text { productivist products }\end{array}$ \\
\hline Risk & $\begin{array}{l}\text { Adverse health } \\
\text { side-effects }\end{array}$ & Crop cross-pollination & $\begin{array}{l}\text { Monopoly market; lack } \\
\text { of choice }\end{array}$ \\
\hline $\begin{array}{l}\text { Power and } \\
\text { control }\end{array}$ & $\begin{array}{l}\text { Substantial equiva- } \\
\text { lence; precautionary } \\
\text { principle }\end{array}$ & $\begin{array}{l}\text { Food security; food } \\
\text { monopoly; crop } \\
\text { coexistence }\end{array}$ & $\begin{array}{l}\text { Labelling of GM } \\
\text { products }\end{array}$ \\
\hline
\end{tabular}

of changes in value systems, representing a change from a materialist to a post-materialist value orientation that has recently been evident in European societies (Inglehart 1990; Lowe et al. 1993). This value shift can be superimposed on the ethical continuum of utilitarianism and deontology. The obvious utilitarian gains of the agriindustrial model are becoming less significant than the gains in sustainability and wellbeing of the post-productivist model. It seems that society is looking beyond the material improvements in the quantity and price of food and, as in Maslow's pyramid, attempting to incorporate what are often held to be the higher values that are required to actualize societal inspirations (Levidow et al. 2012). These values are entrenched in the process of governance in Europe, through the various treaties of the European Union, as justice, freedoms, rights, sustainability, dignity, solidarity and equality (see Chap. 5), and some of them influence the arguments and perceptions of stakeholders.

The discourses on innovation, risk, and power and control overlap in terms of argumentation embedded in scientific complexity, human values and socioeconomic impact. The discourse of innovation and its focus on economic prerogatives cannot be clearly differentiated from that of risk, with its focus on individual effects, or that of power and control, which attempts to balance the two in a societally sustainable manner.

The relevant values themselves are used more as guiding principles than as defined legal concepts. The values of justice, equality, sustainability, freedoms and rights that are dominant in European societies show significant overlaps (and even contradictions) when it comes to real-life applications. Nevertheless, it is neither counterproductive nor undesirable to attempt a categorization of a scientific debate in terms of values and discourses, as long as there is clarity of source and purpose in the debate process. Table 9.1 summarizes the main arguments in terms of dominant value and type of discourse in food technologies.

\subsubsection{Justice and Equality}

Justice and equality are combined in Table 9.1 because the overlap in the relevant argumentation is sufficient to make them indistinguishable. Both refer to attempts to uphold fairness in societal dealings, rejecting prejudice or preference 
of treatment for one group over another. The innovation discourse derived from these values deals with two main arguments, the more straightforward of which focuses on the opportunity for new food technologies to provide for societal prosperity through economic development. This argument is promoted for many new technologies. However, the European food industry is substantial. Failure to adopt new technology may have an impact on many people, including employees and consumers. Equality is interpreted in this case in terms of (equal) access to work and food products. Preventing the implementation of a technology with direct health benefit effects runs contrary to the values of justice and equality (i.e. fair and equal access to wellbeing). Against this, an increase in injustice and inequality may be associated with products of new technology that are prized more highly than equivalents perceived as less healthy, and may be unaffordable for less affluent citizens.

The discourse of risk focuses on technical details, namely whether novel foods carry any risks to human or animal health. This discourse is also the least conclusive in terms of values. Justice and equality would prohibit the unnecessary taking of risks, particularly if these are distributed inequitably across the population. From here, it could be argued that food technologies may represent a risky experiment with human health and wellbeing, therefore breaching the value of justice.

The power and control discourse is where justice and equality are enshrined in law. For example, the interplay between two different arguments relating to risk assessment has been observed: substantial equivalence versus the precautionary principle. From a global perspective, substantial equivalence represents a just and equal risk assessment process, and its abandonment creates unfairness and inequalities in international relations. The opposite might be true for the precautionary principle applied at the level of the individual: it promotes fairness and equality for citizens who do not agree with the status quo and are unwilling to become what they see as research subjects.

\subsubsection{Sustainability}

The value of sustainability refers mainly to environmental protection, which includes the environment seen as a resource for future generations. Thus sustainability relates to the way in which, and reasons why, food is produced. Innovation discourse revolves around the specific characteristics of food crops and their relationship to the environment. New technologies may be promoted as a solution to environmental threats (diseases), conditions (extreme climate) and energy production (biofuels) that otherwise would be impossible or expensive to achieve. As such, it is argued that technologies promote a cleaner and more sustainable environment.

The sustainability risk discourse focuses on the introduction into the environment of novel crops that cannot be separated from the current ones. For example, cross-pollination may result in diminished biodiversity. 
The primary policy issue (i.e. regarding how to develop and maintain food security) is whether existing environmental conditions are sufficient to produce a sustainable source of food for the increasing human population. New food technologies have the potential to improve food security. At the same time, domination by a small number of profitable enterprises could create the opposite effect: a world where biodiversity is dwindling while what remains is governed by a few. Evidence in favour of developing a sustainable coexistence strategy is required scientifically, and legislative hurdles may be associated with its implementation.

\subsubsection{Freedoms and Rights}

The values of freedoms and rights are almost interchangeable. In the innovation discourse on food technologies, both proponents and opponents argue that citizens should have the right and the freedom to choose between products deriving from either agri-industrial or post-productivist types of agriculture. This usually, but not always, translates into choices between organic, nonorganic and genetically modified (GM) foods in Europe. What differentiates the arguments is not whether choice should exist, but how society should achieve it. The issue of intellectual property rights (IPR) is located in the risk discourse. IPR can have significant effects on the availability of food on the market, thus creating dangerous market shifts. For instance, extensive IPR protection could lead to monopolies, while weak protection could lead to lack of innovation. Different perspectives are not easily reconcilable.

The power and control discourse in Europe has focused primarily on the issue of labelling, in which the freedom to choose is associated with the right to know. Despite opposition by the food industry, the use of labelling to identify products containing or derived from GM material has been viewed as a basic right and has been legislated as such. The only undecided issue is the level of tolerance for new technology (i.e. GM) ingredients that is acceptable for labelling purposes.

\subsubsection{Ethics and Public Perceptions}

Dominant values are not easily distinguishable in public discourse because they permeate all argumentation. Reflective discourses may be better represented using a traditional approach to ethics discourse analysis that includes the description of stakeholder perspectives in terms of ethical principles. This analytic approach, termed 'ethical matrix', is inspired by the 'principled approach' in standard biomedical ethics (Bhuiyan 2010).

Such analysis identifies stakeholders' perspectives on fundamental ethical principles, both inward-facing, as they relate to themselves, and outward-facing, in terms of their ethical responsibility to other stakeholders and wider society. It is 
possible that these different perspectives might in some cases be conflicting, even for a single stakeholder. The values individual stakeholders hold can affect the way in which they balance what they perceive as their own interests with those of other stakeholders, of particular importance where the interests and/or perspectives of different stakeholders appear to clash. For example, innovators whose primary focus is on their own freedom to innovate and market their inventions in a way that maximizes financial gain, while avoiding any negative impact on their brand or image, may find themselves in conflict with other stakeholders who see the right to open and transparent information as an essential factor in their freedom to choose and make decisions. Farmers who focus on their freedom to choose whether or not to grow GM crops or animals may find themselves in conflict with other stakeholders who prioritize the protection of human health, the environment or animal welfare, or who perceive GM products as having unidentified potential risks.

Thus it is important for all stakeholders to understand not only their own needs but also the needs and perspectives of other stakeholders. Without a balanced ethical perspective, novel innovations may stall through opposition, or companies may be disincentivized from developing certain new technologies. This is, to a large extent, what has happened in Europe. One argument used by innovators and the food industry is that GM products can increase the food supply and strengthen food security, particularly in the developing world. However, these arguments are irrelevant to Europe, where food is plentiful and consumers feel entitled to make their own choices about the food they eat: they see no reason for exposing themselves to any level of potential risk when there are no evident benefits. It has been argued that consumers in countries suffering chronic food shortages are less concerned, although a number of developing countries have also expressed concerns about GM foods.

If people are struggling to meet their basic physiological needs and perhaps have only one source of food, they are unlikely to reject food whatever its origins. This does not mean that any of their concerns can be ignored. As physiological and safety needs are met, people have greater opportunities to express the ethical principle of autonomy or freedom of choice. They may also have greater opportunity and inclination to express outward-directed or altruistic choices, for example in relation to other communities, animal welfare or the environment.

It is argued by some innovators and policymakers that the benefits associated with GM foods are increasing and that consumer acceptance of GM products would lead to important economic growth. While there is some evidence that consumers are more likely to accept GM products if benefits can be clearly identified, the broader economic-growth argument may be outside the field of interest of most consumers.

Other stakeholders have repeatedly failed to understand or accept the perspectives and values that drive consumer acceptance, arguing that if consumers understood the science, all would be well. Patently this approach does not work. European consumers appear to value their freedom to choose which food products they can buy. Although it is widely recognized that providing consumers with information on real and potential risks and benefits associated with GM foods in 
general is important, this alone is not sufficient to secure consumer acceptance. Labelling provides for consumer choice. Manufacturers argue that consumers perceive that GM products are unsafe.

\subsection{The Indian Case}

Food security has been an extremely serious problem in India over the past 60 years. In the early years of independence, from 1947, India was dependent on food aid programmes. Thus the need for technological intervention to produce higher yields was a national policy priority. The Green Revolution was embraced by the Indian government as a technological response to the increasing gap between food demand and food availability. India was transformed from a fooddeficient country into a leading food producer. The Green Revolution resulted in a record grain output of 131 million tonnes in 1978/1979, establishing India as one of the world's biggest agricultural producers. For example, the crop area under high-yielding varieties of wheat and rice grew considerably (Edugreen n.d.). Capital-intensive agriculture increased economic disparities between large farmers and small farmers.

The change from traditional subsistence farming to industrial monocropping had negative effects on small farmers. They found themselves trapped in a cycle of high interest rates associated with the purchase of seeds, fertilizers and pesticides. Lack of competition meant that prices remained very high (Sebby 2010). The negative socioeconomic and environmental impacts of the Green Revolution are visible today. The institutional and economic conditions for applying Green Revolution technology effectively and safely were not fully in place, particularly for small and marginal farmers. The services needed for small-scale producers to gain access to or to realize the benefits were inadequate, especially for the resource-poor, the indigent and marginalized, and women (McIntyre et al. 2009).

The debate on environmental impact has led to an increase in policy support for organic production. However, post-production losses of perishable and semiperishable products are extremely high.

A further issue relates to inequality in access in relation to Green Revolution technologies that were available to producers in the rich northern states of Punjab, Haryana, parts of Uttar Pradesh, Madhya Pradesh and Maharashtra. This has led to supplementary programmes aimed at improving food security at the subregional level.

The impediments to enhanced food production are also associated with urbanization and market incentive structures that adversely affect areas under cultivation across different crops (Brahmanand et al. 2013). The overall costs of cultivation, largely an outcome of input costs, have increased significantly, pushing up overall food prices. As a result, India witnessed intense political debate, which led to the complete suspension of the whole process of GM commercialization (Chaturvedi et al. 2012; Chaturvedi and Srinivas 2013). 
However, food production techniques have diversified. Technologies like biosensors, genomics, biotechnology and nanotechnology are now being developed and implemented. Technology-led paths should deliver prosperity, sustainability and employment to farming communities.

In India, farmers are increasingly experimenting with indigenous practices associated with alternative agriculture, although research in the area is less frequently funded. Against this, more affluent farmers are adopting advanced technological solutions, largely led and supported by private-sector seed firms.

An ethical analysis can be applied to establishing a linkage between technologies and their socioeconomic aspects, environmental sustainability, the influence of global or external factors and equitable access. The proponents of GM technology base their arguments on the environmental sustainability associated with its introduction. The opponents argue that the research and development infrastructure is very expensive and poorly regulated.

Three discourses - those of innovation, risk, and power and control—overlap, with socioeconomic issues cutting across them. Here the term 'socioeconomic' may seem too vague or broad, but it is possible to identify the key issues of relevance.

The key lessons from this analysis of food technologies in India are:

- Innovation cannot be divorced from broader concerns relating to socioeconomic impacts. Considering such concerns as part of technological innovation policy and management will result in greater benefits to society, increased acceptability and the wider adoption of technologies.

- Power and control should be understood in terms of impacts and how they can result in distorted markets, a less-than-optimum use of technology and societal resistance. The examples from India show that stakeholders may differ about regulatory activities. Those who question technologically based power and control often use socioeconomic discourse to highlight their concerns and to make counterclaims regarding benefits and risks, which are discussed in forums that may be unequal in terms of their influence on the policy process. Regulation and policy must address socioeconomic issues.

- Various technological options have to be assessed and promoted to maximize gains. It is here that assessments of socioeconomic factors have an important role in policy formulation. For example, technological options like non-GM biotechnology, traditional plant breeding and organic agriculture can be supplemented with GM biotechnology.

- Food technologies may ensure better productivity and environmental sustainability. Access, equity and inclusion can be criteria in deciding on and implementing technologies. Socioeconomic impact assessment may be applied in areas ranging from deploying innovation to protecting farmers from vulnerabilities and risks associated with technologies.

In summary: in India, innovation issues cannot be divorced from broader concerns relating to socioeconomic impacts. Addressing these as part of technological innovation policy and management will optimize benefits to society. 


\subsection{The Chinese Case: Genetically Modified Foods in China}

GM food cases in China cannot be discussed without reference to a GM cotton variety that was introduced to the country in the 1990s and rapidly promoted, leading to the establishment of an associated regulatory system.

In 1992, the cotton-growing areas in northern China suffered severely from bollworms, which caused the yield per unit area in Hebei, Shandong and Henan to decline by nearly $30 \%$. The significant decrease in cotton production endangered the textile and related industries (Zhang and Wang 1993; Qiu and Wang 1998). A GM cotton variety developed by Monsanto was introduced to China in 1995 and approved for commercialization by the Ministry of Agriculture. In 1998, this cotton variety was promoted widely in China. Monsanto acquired an advantage in the cotton seed market and quickly became the favoured choice of cotton growers across the country.

Meanwhile, the Chinese government increased efforts to develop related biological technologies. In 1991, the then State Science and Technology Commission of China initiated a research project on the development of insect-resistant GM cotton varieties. By 2005, China had successfully developed more than 30 such varieties, which were grown in nearly all cotton-growing areas, accounting for more than $70 \%$ of the total cultivated area of all insect-resistant cotton varieties. With the improvement of their research and development capacity and their superior knowledge of the needs of domestic cotton growers, Chinese cotton seed breeding companies have achieved rapid development and gradually established a competitive edge in the market. Insect-resistant cotton seeds independently developed by Chinese companies account for $90 \%$ of the domestic market.

With respect to GM foods and related technologies, the Chinese government adopts a largely empirical approach, emphasizing industry security and innovation. However, the process has been not without flaws, for example the lack of concern on the part of the government, researchers and the public regarding the environmental impact of GM crops. Not only consumers, but most cotton growers as well, were ill-informed about transgenic technology, and public knowledge remains limited, even now that GM crops have been promoted. The absence of a forum for stakeholders and the susceptibility of the public to anti-science rumours make it very difficult to conduct an effective dialogue between researchers and the public and to build consensus across groups.

The success in cotton production has given the government, research institutes and agricultural enterprises a deep understanding of the importance of transgenic technology. There is consensus that China should catch up with developed countries in transgenic technology and build its own transgenic technological strengths in agriculture and related fields. China has developed scientific programmes in both basic and applied research that have produced an extensive body of knowledge about biology, thus laying a solid foundation for further research and development. The Chinese government has been very prudent, however, about the 
commercial production of GM crops. Only a limited number of GM varieties such as tomato, papaya and pimento have been approved for commercial cultivation. No permission has been given for the commercial GM cultivation of any staple crop, apart from biosafety certificates being granted to two GM rice varieties and one GM corn variety in 2009. However, the issuing of these certificates did not allow immediate commercial cultivation: to date, no GM staple crop has been approved for commercial cultivation in China.

China is concerned about whether GM foods will cause harm to human health and/or the ecology and environment. There are concerns that the long-term ingestion of the substance containing the Bt toxalbumin found in GM crops may be harmful to health. Supporters of GM foods cite research findings that the toxalbumin produced by the $\mathrm{Bt}$ gene is only toxic to certain organisms. Foreign research institutes have reported that GM foods may have a negative effect on the human liver, kidney and immune system, as frequently cited by the opponents of GM foods. A second concern relates to potential allergens that may be introduced into new crop varieties through GM. Therefore plants with any allergen gene inserted are prohibited from commercialization.

Transgene escape can potentially have negative impacts on the environment. Natural crossing will take place between some cultivated plants and nearby related wild species, introducing the genes of the cultivated plants into the wild species, to the extent that wild plants may take on the characteristics of the GM plants (e.g. pesticide resistance). China's arable land is widely fragmented across farms, and therefore the asylum or refuge method for reducing the ecological impact of the transgenic technology is not feasible. A further risk is that because Chinese agriculture is so highly fragmented, effective governance and monitoring of GM crops is almost impossible and many GM crops are grown illegally ( $\mathrm{Zi} 2005)$.

The Chinese government has identified a further risk issue that could best be described as 'industrial risk', meaning that the globally integrated agricultural production system poses a threat to the agricultural security of developing countries, resulting in problems with access to foods and compromising the survival of millions of people. The population excluded from the economic system may generate political and economic crises in developing countries. Through such means as mergers and acquisitions, control of IPR and specialized production, the multinational agricultural companies, which are based in developed countries, have implemented a vertical integration strategy centred on a few developed countries that control the entire agricultural and food production chain from raw material supply to sales. As multinational agricultural companies become increasingly monopolistic globally, many individual medium and small-sized farms face bankruptcy. Developing countries are gradually losing their independence with regard to food production. Transgenic technologies are mostly controlled by large-scale agricultural and chemical companies in developed countries. As a response, the Chinese government maintains strong vigilance over the potential risks of opening the markets concerned (Magdoff et al. 1998; Shiva 2000; Amin 2003).

At present, China's GM food administration system still faces various problems, including poor coordination and cooperation between different government 
departments, inadequate administrative measures and a lack of public participation, communication and decision-making transparency. From the perspective of policies, laws and regulations, China's regulatory system for GM foods covers the economy, trade, production and environmental protection horizontally and research, experimentation, processing, production, operation, and import and export vertically, but there is still no specialized comprehensive legislation. The regulations issued by the various competent government departments are not only jumbled but also unable to address major biosafety issues that fall outside their scope. Moreover, the lack of coordination of the different laws and regulations has led to overlapping, conflicts or omission in responsibilities between the various departments.

Whether the farmers adopt new technologies is dependent on their cost and promised return. Even though GM seeds are several times more expensive than conventional seeds, the premium is worthwhile in the short term in view of the many benefits they bring, including savings in pesticide costs, the reduced use of labour and the prevention of pesticide-caused poisoning. Therefore farmers are generally willing to adopt these new technologies. In the long term, the degree of acceptance by consumers of GM foods and the implementation of a GM food marking system may lead to changes in demand, and uncertainty in this respect may cause fluctuation in the farmers' expected returns (Ma and Huang 2003; Zhao and Chen 2011; Zheng et al. 2012).

The degree of acceptance by consumers of GM foods will eventually determine their growth. Two surveys in 2002 and 2003 showed that approximately $67 \%$ of urban consumers were aware of transgenic technology and approximately $60 \%$ accepted GM foods (Huang et al. 2006). Comparable surveys in recent years have indicated some improvement in urban consumer awareness of GM foods but a decrease in acceptance (Luo et al 2010; Zhou et al. 2012). The main determinants of consumer attitudes to GM foods are food safety and income. There is a positive correlation between perceived food safety and willingness to buy, and a negative correlation between income and the willingness to buy. Food safety is dependent on information symmetry, which is mainly subject to the influence of media publicity and the degree of trust in the government. The views presented in the media influence the degree of acceptance of GM foods on the part of Chinese consumers.

A Chinese consensus conference on GM foods in 2008 suggested that Chinese consumers, especially those living in large and medium-sized cities, were increasingly worried about GM food, and that the public were paying closer attention to the risks of biotechnology, particular in relation to GM foods. The Chinese public in general trust the government and scientists, a confidence that is enhanced by direct dialogue among the parties. The public are cautious about the development of GM, but supportive of the country's efforts in developing GM technology.

In China, the discourse on supporting GM foods and related technologies through innovation involves two intertwined systems. The first is the discourse of developmentalism, which holds that only by giving full scope to the advantages of biological technology and using transgenic technology to transform products into productivity can China's agriculture undergo fundamental changes. 
It further states that transgenic technology will improve the inherent value of traditional agriculture because the reduced production costs and improved outputs will increase agricultural productivity. Thus, it is argued, the development of GM foods is a long-term global agricultural trend, and will help solve China's future food security problems. The second is the discourse of scientism, which, starting out from Deng Xiaoping's judgment that 'science and technology constitute a primary productive force' (Deng 1994), holds that GM foods naturally have political legitimacy and that the aura of science lends scientists and technologies an authority and reputation that tend to foreclose reflection on the legitimacy and social consequence of GM foods, thus endowing them with an automatic correctness.

The production and consumption of GM foods in China are also associated with potential risks-in general, and specifically in relation to China's existing agricultural situation and administration, and to the industry security. The Chinese government does not want to see the country's industrial security undermined either by foreign control of key technologies or by China's own lack of technological preparation.

The Chinese government has a mixed attitude towards GM food technology. On one hand it is prudent about the commercial application of relevant technologies and, on the other, it takes research and development and independent possession of transgenic technologies as a strategic policy for supporting agricultural development at the national level.

\subsection{Conclusions from the Three Regions Analysis}

A number of important factors affect the way in which policy is elaborated and established for the development and implementation of innovative food technologies in the three regions. The identity of the key actors and their position in relation to power and control influence policy implementation. Local food security considerations and socioeconomic factors are also relevant, particularly as they affect regional and national economies and global competitiveness. The role of ethical considerations depends on the extent to which such values influence these factors.

In Europe, consumers play a crucial role in developing policy and influencing the extent to which innovative food technologies are introduced. The European consumers' response to technologies such as GM food has carried considerably more weight in the market than pure economic considerations. In the European context, regulatory transparency, risk perception and communication, fairness, trust and freedom of choice underlie and influence the extent to which consumer opinion affects novel food technology policies. It is useful to compare this expression of values in Europe with their relative influence in the different political, societal and economic situations of China and India.

The Chinese case study focuses specifically on the use of GM in agriculture. The introduction of food technology has been influenced by a different relationship 
between the state and its citizens. Associated policy appears to be influenced largely by Chinese scientific research, closely allied to government policies on the need to ensure economic independence and control, which are related in turn to an ideological perspective on the ability of science to deliver economic benefit.

Although public concern about GM food is increasing in China, there appears to be relatively little direct engagement, either with public interest groups or with Chinese consumers, to ascertain whether there are any ethical or other values held by citizens that may impact on the introduction of such food. At the same time, the Chinese government is aware of the need to protect its citizens from any risks associated with GM products, and recognizes that there is little point in introducing GM staples into the food chain if these are likely to be rejected by consumers. This demonstrates that the Chinese government is concerned about its ethical responsibility to protect its citizens from harm and acknowledges consumers' right to choose whether or not to consume GM food products. Although trust in government, regulators and scientists may be higher in China than in Europe, the principle of consumer informed choice through the informative labelling of foods produced using new technologies may well still be an important consumer condition of acceptance of GM foods, and potentially other innovative food technologies (Coles and Frewer 2013).

In India, agrifood innovation cannot be divorced from broader socioeconomic impacts (effects on small farmer communities, the environment, labour costs, traditional agriculture, etc.). Stakeholder debates are often based on socioeconomic concerns. Discussion of putative risks (and associated policy measures) is an important issue in India, while food security is a major preoccupation for policymakers. Traditional plant breeding and organic agriculture too are important in Indian agricultural production.

Food policy in India is also influenced by various interest groups and/or trade bodies for which socioeconomic considerations (based on access, equity and inclusion) are key value considerations. This appears to have produced a number of very pragmatic policy choices that aim to sustain and develop organic agriculture while at the same time making room for the sustainable implementation of biotechnology innovations.

\subsubsection{Regional Commonalities}

Taken together, certain similarities between the three regions offer a road map for collaboration. Public multi-stakeholder debates are becoming the norm, rather than the exception, in all regions. The proximity of food to consumer-citizens and a strong and increasingly educated and assertive civil society in all three regions are changing the rules of policy debates. To an increasing extent, policy agendas are influenced by the outcomes of multi-actor and multi-stakeholder public interaction. Understanding the social dimensions of new food technologies may become an important consideration in the policy process. 
The growing vocalization of consumer concerns may lead to a shift of balance in the power and control spectrum. As the existing risk assessment paradigm is questioned, measurements of long-term effects are becoming prominent elements in the official risk assessment process that require a greater emphasis on collaborative activities in constructing a new common procedure.

While there are similar concerns in all three regions about issues of risk and safety and how these are expressed, the mechanism to deal with these still varies considerably. The precautionary principle plays a major role in the European context, and is also now taken into account by the World Trade Organization and the Codex Alimentarius. In India, the focus is on developing an increasingly stringent regulatory framework for food safety with the introduction of the National Food Security Act of 2013 and a new regulatory body, the Food Safety and Standards Authority of India in the Ministry of Health and Family Welfare. In China, although the precautionary approach operates in relation to the introduction of GM staple foods, the ideological scientism position is still an important consideration.

Despite these differences, in the context of a global market in food products, some clarification of parameters for a common approach to global risk assessment standards is required. In any common collaborative activity between the three regions, food security has to be accepted as a valid indicator of the potential impact and value assessment of new technologies. A commonly understood socioeconomic analysis is also required as a basis for policy development.

The engagement of the public and stakeholders in food debates is increasingly seen as an integral part of the policy process. Participatory technology assessment exercises have been conducted in all three regions (e.g. consensus conferences), but formal institutional structures are missing in China and India (see Chap. 4). Some context-based structures that presuppose a common understanding of methodological parameters in public engagement should be developed in pursuit of collaborations that will see an integrated food policy input in the three regions.

Open Access This chapter is distributed under the terms of the Creative Commons Attribution Noncommercial License, which permits any noncommercial use, distribution, and reproduction in any medium, provided the original author(s) and source are credited.

\section{References}

Amin S (2003) World poverty, pauperization and capital accumulation. Mon Rev 55(5):1-9

Bhuiyan A (2010) Ethical challenges of animal biotechnology: application of Ben Mepham's ethical matrix. Doctoral dissertation. Linköpings Universitet

Brahmanand PS, Kumar A, Ghosh S, Chowdhury SR, Singandhupe RB, Singh R, Nanda P, Chakraborthy H, Srivastava SK, Behera MS (2013) Challenges to food security in India. Curr Sci 104(7):841-846

Chaturvedi S, Srinivas KR, Joseph R, Singh P (2012) Approval of GM crops. Econ Polit Wkly 47(23):53-61

Chaturvedi S, Srinivas KR (2013) Genetically modified crops: policy logjam. Econ Polit Wkly 48(14):19-23 
Coles D, Frewer LJ (2013) Nanotechnology applied to European food production: a review of ethical and regulatory issues. Trends Food Sci Technol 34(1):32-43

Deng Xiaoping (1994) Selected works of Deng Xiaoping vol. III (1982-1992)

Edugreen (n.d.) The green revolution. Energy and Resources Institute, New Delhi. http://edugreen.teri.res.in/explore/bio/green.htm. Accessed 6 June 2014

Huang J, Qiu H, Bai J, Carl P (2006) Awareness, acceptance and willingness to buy genetically modified foods in urban China. China Soft Sci 2:61-67

Inglehart R (1990) Culture shift in advanced industrial society. Princeton University Press, Princeton NJ

Levidow L, Birch K, Papaioannou T (2012) EU agri-innovation policy: two contending visions of the bio-economy. Crit Policy Stud 6(1):40-65

Lowe P, Murdoch J, Marsden T, Munton R, Flynn A (1993) Regulating the new rural spaces: the uneven development of land. J Rural Stud 9(3):205-222. http://www.sciencedirect.com/science/article/pii/074301679390067T. Accessed 8 June 2014

Luo Z, Liu Z, Huang W (2010) Study on consumer cognition and acceptance of genetically modified products: a case study of general public and university students in Nanjing. J Anhui Agric Sci 38(29):16621-16623

Ma S, Huang Z (2003) Farmers' households, government and genetically modified agricultural products: an analysis of farmers' intentions to grow genetically modified crops in China. Chinese Rural Econ 4:34-40

Magdoff F, Buttel FH, Foster JB (eds) (1998) Hungry for profit: agriculture, food, and ecology. Mon Rev 50(3):1-160

McIntyre BD, Herren HR, Wakhungu J, Watson RT (eds) (2009) Agriculture at a crossroads: global report. In: International assessment of agricultural knowledge, science and technology for development (IAASTD). Island Press, Washington DC

Qiu J, Wang J (1998) Historical analysis and development strategy of cotton production in China. Dev Res 4:49-52

Sebby K (2010) The green revolution of the 1960's and its impact on small farmers in India. Environmental studies undergraduate student theses, paper 10. University of Nebraska, Lincoln NE. http://digitalcommons.unl.edu/envstudtheses/10. Accessed 8 June 2014

Shiva V (2000) Stolen harvest: the hijacking of the global food supply. South End Press, Boston MA

Zhao C, Chen S (2011) An analysis of farmers' cognition of transgenic seed market: evidence from a survey of Shanxi Hebei and Shandong provinces. Agric Technol 31(02):1-6

Zhang X, Wang R (1993) Analysis of the reduction of cotton production in 3 provinces and the suggestion on cotton production (in Mandarin). China Cotton 2:4-8

Zheng Y, Wang C, Chen A, Xue C (2012) Farmers access to transgenic technology services: evidence from Papaya production in Guangdong. Agric Eng 2(2):101-105

Zhou H, Qi Z, Feng L (2012) Empirical research of consumers' cognition of GMF. J Huazhong Agric Univ (Soc Sci Ed) 2:56-60

Zi X (2005) GM rice forges ahead in China amid concerns over illegal planting. Nat Biotechnol 23(6):637 